\title{
LITERATURE REVIEW Effects of bariatric surgery on the central nervous system and eating behavior in humans: a systematic review on the neuroimaging studies
}

\author{
Efeitos da cirurgia bariátrica no sistema nervoso central \\ e comportamento alimentar em humanos: uma revisão \\ sistemática dos estudos de neuroimagem
}

Hélio Tonelli', Fernanda Mattias Sartori', João Caetano Dallegrave Marchesini', João Batista Marchesini', Denise Gianoti Tonelli

\begin{abstract}
Introduction: Neuroimaging studies suggest that obese people might show hyperactivity of brain areas regarding reward processing, and hypoactivity of brain areas concerning cognitive control, when exposed to food cues. Although the effects of bariatric surgery on the central nervous system and eating behavior are well known, few studies have used neuroimage techniques with the aim of investigating the central effects of bariatric surgery in humans. Objectives: This paper systematically and critically reviews studies using functional neuroimaging to investigate changes on the patterns of activation of central areas related to the regulation of eating behavior after bariatric surgery. Method: A search on the databases Medline, Web of Science, Lilacs and Science Direct on Line, was conducted in February 2013, using the keywords "Neuroimaging", "Positron-Emission Tomography", "Magnetic Resonance Imaging", "Gastric Bypass", "Gastroplasty", "Jejunoileal Bypass", "Bariatric Surgery". Results:

Seven manuscripts were included; the great majority studied the central effects of Roux en $Y$ gastric bypass, using positron emission tomography or functional magnetic resonance. Conclusions: Bariatric surgery might normalize the activity of central areas concerned with reward and incentive salience processing, as the nucleus accumbens and mesencephalic tegmental ventral area, as well as circuitries processing behavioral inhibition, as the dorsolateral prefrontal cortex.
\end{abstract}

\section{Keywords}

Neuroimaging, functional magnetic resonance, positron emission tomography, gastric bypass, bariatric surgery.

\section{RESUMO}

Introdução: Estudos de neuroimagem sugerem que indivíduos obesos podem apresentar hiperatividade de áreas cerebrais associadas à recompensa e hipoatividade em áreas associadas ao controle cognitivo quando expostos a pistas alimentares. Apesar do conhecimento dos efeitos da cirurgia bariátrica sobre o sistema nervoso central e sobre o comportamento alimentar, poucos estudos empregaram técnicas de neuroimagem para estudar os efeitos centrais da cirurgia bariátrica em humanos. Objetivos: $O$ presente trabalho revisa sistemática e criticamente os estudos de neuroimagem funcional a respeito das alterações na ati-

1 Clínica Marchesini.

2 Pontifícia Universidade Católica do Paraná (PUC-PR).

Correspondence address to: Hélio Tonelli

7/29/2013

Approved in

10/15/2013

E-mail: hatonelli@gmail.com 


\section{Palavras-chave}

Neuroimagem, imagem por ressonância magnética, tomografia por emissão de pósitrons, derivação gástrica, cirurgia bariátrica. vação de regiões centrais relacionadas à regulação do comportamento alimentar após a cirurgia bariátrica. Método: Foi realizada uma busca nas bases de dados Medline, Web of Science, Lilacs e Science Direct on Line, em fevereiro de 2013, utilizando-se as palavras-chave "Neuroimaging", "Positron-Emission Tomography", "Magnetic Resonance Imaging", "Gastric Bypass", "Gastroplasty", "Jejunoileal Bypass", "Bariatric Surgery". Resultados: Foram incluídos sete trabalhos, dos quais a grande maioria estudou os efeitos centrais do bypass gástrico em $Y$ de Roux empregando tomografia por emissão de pósitrons ou ressonância magnética funcional. Conclusões: A cirurgia bariátrica parece regular a atividade de áreas centrais associadas ao processamento da recompensa e da saliência de incentivo diante de pistas alimentares, como o núcleo accumbens e a área tegmental ventral do mesencéfalo, e também de circuitos neurais que processam a inibição comportamental, como o córtex pré-frontal dorsolateral.

\section{INTRODUCTION}

Modern societies have high rates of chronic diseases such as hypertension, diabetes and obesity'. In developed countries, where the incidence of obesity is increasing, most of the cases result from a combination of genetic, behavioral and environmental factors'.

We humans eat not only for nourishment, but also for pleasure. Subcortical regions that process the reward associated with food, such as the mesencephalic ventral tegmental area (VTA) and the nucleus accumbens (NAC), have a key role in the configuration of complex cognitive mechanisms causing craving and search for food from environmental cues $^{2}$. The feeding behavior whose main goal is to supply the body with the necessary nutrients for survival is called homeostatic feeding, whereas the non homeostatic or hedonic feeding behavior comprises the behavioral repertoire of searching for foods triggered by the activation of brain systems associated to reward and motivation?.

The hedonic feeding behavior has a special place in modern societies, where overeating and cravings for specific types of foods are crucial factors in the emergence of obesity'. Although hedonic and homeostatic pathways are usually studied separately, it is known that both circuitries are widely interconnected. Arguably, the subjective experiences of pleasure while eating unpalatable food when one is hungry, as well as the cravings for high-calorie foods in satiated individuals, stand for evidences of such interconnections'.

Multiple obesogenic influences lie behind the obesity epidemic in urban centers ${ }^{3}$ and some factors make this condition a challenge to all healthcare professionals involved in the understanding of its pathophysiology and treatment. Among them, we have, on a physiological level, the complexity of the central and peripheral systems of regulation of feeding behavior and energy expenditure ${ }^{4}$ and, on a behavioral level, individual differences in the psychological and behavioral outcomes of the susceptibility to environmental opportunities for eating 5 .

Bariatric surgery has been considered one of the most effective treatments for morbid obesity and associated comorbidities $^{6}$. Its effects on weight seem to derive not only from the resulting physical restriction to food, but also from the reduction of hunger and appetite and promotion of satiety and possibly from an increase of energy expenditure. These physiological effects and their behavioral counterparts occur through actions mediated, at least partially, by the central nervous system (CNS) .

Neuroimaging studies using positron emission tomography (PET), functional magnetic resonance (FMR) and magnetic resonance (MR) have provided insights into the neurobiology of feeding behavior in humans, largely regarding the link between eating attitudes in obese and neural pathways associated with reward and motivation, as well as the ability to control an impulse to eat caloric foods ${ }^{3}$. Such studies suggest that obese individuals might exhibit hyperactivity of brain areas associated with reward, emotion, memory, and sensorimotor processing, and hypoactivity in areas associated with cognitive control ${ }^{4}$, which is defined as the brain's ability to coordinate the processing of millions of neurons in order to achieve specific behavioral goals?.

Despite the large number of neuroimaging studies focusing on obesity and the growing knowledge of the actions of bariatric surgery on the CNS and feeding behavior, few studies have used this methodology to study putative central effects of bariatric surgery in humans.

This paper systematically and critically reviews studies using functional neuroimaging to investigate changes on the patterns of activation of central areas related to the regulation of eating behavior after bariatric surgery, searching for neuroimaging studies focusing on CNS functional changes in brain circuits associated to hedonic or homeostatic feeding behavior, and / or cognitive control in bariatric patients. 


\section{METHODS}

We conducted an electronic search on the databases Medline, Web of Science, Lilacs and Science Direct on Line, in February 2013, for manuscripts published in English or in Portuguese.

Phrases for searching databases and their findings were:

1. Medline: ("Gastric Bypass" [Mesh]) AND "PositronEmission Tomography" [Mesh]: 4 articles, out of which $1^{8}$ was selected; ("Gastric Bypass" [Mesh]) AND "Magnetic Resonance Imaging" [Mesh]: 31 articles, out of which 2 were selected9,10; ("Gastroplasty" [Mesh]) AND "Positron-Emission Tomography" [Mesh]: 0 Article, ("Gastroplasty" [Mesh]) AND "Magnetic Resonance Imaging" [Mesh]: 13 manuscripts, none of which was selected; ("Jejunoileal Bypass" [Mesh]) AND "Positron-Emission Tomography" [Mesh] and ("Jejunoileal Bypass" [Mesh]) AND "Magnetic Resonance Imaging" [Mesh], both resulting none article.

2. Web of Science: "Gastric Bypass AND PET" (title): 1 manuscript"; "Gastric Bypass AND Magnetic Resonance Imaging": 1 manuscript, which was not selected; "Gastroplasty AND PET" and "Gastroplasty AND Magnetic Resonance Imaging", both retrieved no articles.

3. Lilacs: "Bariatric surgery AND Magnetic Resonance Imaging" (title): 46 articles, out of which only one was elected ${ }^{9}$ and "Bariatric surgery AND PET": 6 articles, out of which only one was selected ${ }^{8}$.

4. Science Direct on Line: "Bariatric surgery AND neuroimaging" (title): 143 articles, out of which only 2 were elected $^{12,13}$.

Out of the 6 studies initially selected, 2 were found in more than one database ${ }^{8,9}$ (Medline and Lilacs). An additional item was included as a suggestion of database Medline ${ }^{14}$.

The disparity between the great amount of retrieved articles and the small number of eligible ones is justified by the fact that many of the neuroimaging studies which included bariatric patients actually did not have the aim of studying central circuits associated with the regulation of feeding behavior; such manuscripts were in that case excluded.

\section{RESULTS}

Out of the seven initially selected manuscripts, the vast majority (6) evaluated patients undergoing Roux-en-Y gastric bypass (RYGBP) $)^{8-11,13,14}$ and a single one ${ }^{12}$ evaluated patients undergoing adjustable gastric band (AGB). One of the studies included subjects undergoing experimental RYGBP or vertical sleeve gastrectomy (VSG) ${ }^{13}$, although the authors' main purpose was not to investigate differences in the effects of these techniques on the CNS.

The vast majority of experimental subjects were female.
The neuroimaging techniques employed by the researchers were PET ${ }^{8,11,13}$ and $\mathrm{FRM}^{9,10,12,14}$.

PET based papers studied the expression of dopamine receptors before and after bariatric surgery ${ }^{8,13}$ and the activation of diverse brain regions in operated and nonoperated obese individuals and lean subjects, in fasting and after feeding states ${ }^{11}$.

Dunn et al. ${ }^{13}$ and Steele et al. ${ }^{8}$ have conflicting findings, since the former documented reduced expression of dopamine receptors in areas associated with homeostatic and hedonic feeding behavior and the latter documented an increased expression of such receptors in areas associated with hedonic feeding.

Hunt et al. ${ }^{11}$ reported a post-feeding decrease of the glucose radioisotope uptake within the precuneus, prefrontal cortex and thalamus in bariatric obese, but not in non-operated obese.

FMR based papers assessed brain activation in response to visual and/or auditory cues of caloric and non-caloric foods, in fasting or after feeding states, before and after bariatric surgery ${ }^{9,10,12,14}$. Neuroimaging data were correlated with scores on scales measuring satiety ${ }^{11}$, desire for food ${ }^{9}$, motivation to eat ${ }^{12}$, hunger and sensation of plenitude ${ }^{10}$ and desire/pleasure associated with cues about caloric and noncaloric foods ${ }^{14}$.

In most cases, the manuscripts employing FMR are in agreement that operated obese patients display decreased activity within areas directly or indirectly associated with motivation for food (ATV, ventral striatum, putamen, insula, medial prefrontal cortex $[\mathrm{MPFC}]$, precuneus and cingulate) 9,10,12,14 and areas associated with inhibitory control, such as the dorsolateral prefrontal cortex (DLPFC) ${ }^{14}$.

All the manuscripts evaluated also suggest that bariatric surgery, particularly RYGBP, has a favorable effect on the function of central circuits regarding feeding behavior and, therefore, the outcomes on the weight should not be understood solely as resulting from a post-surgical restriction to food. Although the central actions of bariatric surgery are still far from being understood, it has been postulated that they may originate from changes in the concentrations of gut hormones such as ghrelin, peptide YY (PYY) and glucagonlike peptide 1 (GLP-1), though one of the evaluated studies failed to demonstrate this ${ }^{10}$.

The table 1 summarizes the demographic characteristics, methodology and main findings of each of the selected studies.

\section{DISCUSSION}

The large number of neuroimaging studies demonstrating that obese subjects show brain responses to food intake or to visual/auditory food cues that are different from those of 
Table 1.

\begin{tabular}{|c|c|c|c|}
\hline $\begin{array}{l}\text { Authors and year of } \\
\text { publication }\end{array}$ & Demographic characteristics of the sample & Methodology & Main findings \\
\hline Dunn et al., $2010^{13}$ & $\begin{array}{l}\text { Five women ( } 46 \pm 2 \text { years; weight }=118 \pm 6 \mathrm{~kg} \text {, } \\
\text { body mass index (BMI) of } 43 \pm 3 \mathrm{~kg} / \mathrm{m}^{2} \text { ) were } \\
\text { studied pre- and postoperatively ( } 7 \text { weeks after } \\
\text { surgery: } 4 \text { underwent RYGBP and 1, VSG) }\end{array}$ & $\begin{array}{l}\text { Subjects were evaluated with PET with falipride as a } \\
\text { radioligand for the D2 receptor }\end{array}$ & $\begin{array}{l}\text { The authors documented decrease in the expression } \\
\text { of } D 2 \text { receptors in caudate, putamen, ventral } \\
\text { striatum, hypothalamus, substantia nigra and } \\
\text { medial thalamus after surgery }\end{array}$ \\
\hline Steele et al., $2010^{8}$ & $\begin{array}{l}\text { Five women aged } 20 \text { to } 38 \text { years and mean BMI of } \\
45 \text { were studied pre and post operatively (about } 6 \\
\text { weeks after RYGBP) }\end{array}$ & $\begin{array}{l}\text { Experimental subjects were assessed with a PET } \\
\text { radioligand for the D2 receptor, [C-11] raclopride }\end{array}$ & $\begin{array}{l}\text { D2 receptors expression was increased after } \\
\text { bariatric surgery, an increase apparently } \\
\text { proportional to the amount of weight loss }\end{array}$ \\
\hline Hunt et al., 2011"11 & $\begin{array}{l}\text { The authors compared four groups of experimental } \\
\text { subjects: } 4 \text { individuals post RYGBP, } 7 \text { non-operated } \\
\text { obese, insulin-sensitive; } 7 \text { non-operated individuals, } \\
\text { insulin-resistant; and } 8 \text { normal weight subjects }\end{array}$ & $\begin{array}{l}\text { Subjects underwent PET with [18F]- } \\
\text { fluorodeoxyglucose during fed and fasting states }\end{array}$ & $\begin{array}{l}\text { The authors reported decreased radioligant uptake } \\
\text { after feeding in the precuneus, DLPFC, OFC, and } \\
\text { thalamus, but only in the post- RYGBP group }\end{array}$ \\
\hline Ochner et al., $2011^{9}$ & $\begin{array}{l}\text { Ten women (BMI } 40-54 \mathrm{~kg} / \mathrm{m}^{2} \text {; ages between } 20 \\
\text { and } 47 \text { years) were evaluated one month before and } \\
\text { after RYGBP }\end{array}$ & $\begin{array}{l}\text { Study on FRM brain activation in response to visual } \\
\text { and auditory cues of high and low calorie food, } \\
\text { before and after surgery }\end{array}$ & $\begin{array}{l}\text { Authors reported decreased brain activation within } \\
\text { key areas of the mesolimbic reward circuits in } \\
\text { response to high calorie food cues }\end{array}$ \\
\hline Bruce et al., 2011'12 & $\begin{array}{l}\text { Ten obese patients ( } 9 \text { women and } 1 \text { man, mean age: } \\
40.10 \pm 10.27 \text { years; mean BMI before AGB: } 40.6 \pm \\
1.96 \mathrm{~kg} / \mathrm{m}^{2} \text {, mean BMI } 12 \text { weeks after surgery: } 36.1 \\
\pm 2.32 \mathrm{~kg} / \mathrm{m}^{2} \text { ) }\end{array}$ & $\begin{array}{l}\text { Subjects were scanned with FRM before and twelve } \\
\text { weeks after AGB, in fast and fed states. During the } \\
\text { scanning they were shown neutral stimuli and food } \\
\text { cues based stimuli }\end{array}$ & $\begin{array}{l}\text { The authors reported decreased activation of } \\
\text { regions implicated in reward and motivation and } \\
\text { increased activation of anterior PFC areas, after } \\
\text { exposure to food cues }\end{array}$ \\
\hline Ochner et al., 2012 & $\begin{array}{l}\text { Five women (BMI: } 44 \pm 3.8 \mathrm{~kg} / \mathrm{m}^{2} \text { and age } 36 \pm 13 \\
\text { years) were evaluated before and } 1 \text { month after } \\
\text { RYGBP }\end{array}$ & $\begin{array}{l}\text { Auditory and visual stimuli of high and low calorie } \\
\text { foods were presented during FRM scannings, which } \\
\text { were performed during fasting and after feeding }\end{array}$ & $\begin{array}{l}\text { Before the surgery, neural responsiveness was } \\
\text { higher in fasting state in contextual areas such as } \\
\text { the precuneus. Reductions in neural responsiveness } \\
\text { to cues of high-calorie foods within the gustatory } \\
\text { cortex and prefrontal areas linked to motivation, } \\
\text { as well as inhibitory areas were reported in fasting } \\
\text { state, after RYGBP }\end{array}$ \\
\hline Ochner et al., 2012 & $\begin{array}{l}\text { Fourteen women, aged between } 21 \text { and } 54 \text { years, } \\
\text { mean BMI before surgery }=44 \pm 3.8 \mathrm{~kg} / \mathrm{m}^{2}\end{array}$ & $\begin{array}{l}\text { Participants were scanned with FRM while receiving } \\
\text { distinct visual and auditory stimuli about high and } \\
\text { low calorie food, as well as and neutral stimuli, } \\
\text { one month before and after RYGBP }\end{array}$ & $\begin{array}{l}\text { The authors reported reductions in mesolimbic } \\
\text { responsiveness and decreased activation of } \\
\text { inhibitory regions such as DLPFC after surgery }\end{array}$ \\
\hline
\end{tabular}

lean individuals ${ }^{3}$ has stimulated the research into possible changes of such disruptive patterns of neural response to food or to food stimuli after bariatric surgery.

Central neurotransmitters associated to mechanisms of motivation, reward and pleasure as dopamine, endogenous opioids and gamma-aminobutyric acid (GABA) and brain structures involved in the processing of such mechanisms, as NAC, TVA and medial prefrontal cortex (MPFC), as well as in cognitive control, as DLPFC, seem to have their functions "adjusted" after bariatric surgery, at least acutely. Longterm studies will determine whether such "adjustments" can be long lasting. From a clinical standpoint, the results of the studies here reviewed demonstrate that, contrary to common sense, bariatric surgery may constitute a method with therapeutic effects that go beyond the physical constraint to food, promoting actions also in the central regulation of feeding behavior.

Berridge et al..$^{15}$ proposed that the reward sensation associated with food could be divided into three components: "liking", "wanting" and "learning". According to these authors, whose model was proposed from studies with animals, "liking" refers mainly to the pleasure acutely obtained from the food, being primarily mediated by opioid, endocannabinoid and gabaergic neurotransmission. "Liking" can be objectively measured both by the analysis of characteristic behaviors in experimental animals (and typical facial expressions in humans), as by functional neuroimaging studies showing that this sensation is associated with activation of cortical and subcortical structures where hedonic hotspots are located. Hedonic hotspots are found mainly in the NAC and ventral pallidum, and constitute brain areas where neurotransmitters potentiate the sensation of pleasure. "Wanting" is decoupled physiologically and neurobiologically of "liking" and comprises a subjective experience of motivation to seek or to approach and consume a particular kind of food, rather than a mere feeling of pleasure, and it was also described by Berridge et al. as "incentive salience". Subcortical structures such as the mesencephalic dopaminergic projections, which send fibers to structures such as the NAC, amygdala and hippocampus ${ }^{16}$ through the medial forebrain bundle (MFB) ${ }^{17}$ mediate this behavioral response, that includes dopamine as the main neurotransmitter. The activation of dopaminergic pathways appears to increase "wanting" without modifying "liking" and, inversely, dopamine antagonists such as antipsychotics decrease "wanting" without affecting "liking". Because it is processed subcortically, incentive salience 
is simpler and different from more elaborated forms of "wanting", usually associated with a drive for specific foods. Such specific types of "wanting" encompass more cognitive characteristics than incentive salience, and are processed by the cortex. On one hand, DLPFC exerts a "top-down" effect on the activity of subcortical hedonic pathways inhibiting its activity, and consequently, discouraging the behavioral components of incentive salience, on the other, the same frontocortical regions receive inputs from the mesencephalic dopaminergic circuitry that are crucial for processes of learning through reward decoding". "Learning" encompasses Pavlovian conditioning, in which innate or unconditioned stimuli, when paired with neutral stimuli, are transformed into conditioned stimuli, loaded with "wanting" features ${ }^{15}$. "Learning" also includes prediction error signaling, in which unforeseen events trigger the activity of dopaminergic neurons, in order to mobilize attention and favor the incorporation of new information ${ }^{18}$ to a previous collection of food preferences.

PET studies by Dunn et al..$^{13}$ and Steele et al. ${ }^{8}$ are based on the assumption that obese individuals display deficits in dopaminergic transmission leading them to suffer from a "Reward Deficiency Syndrome" which would express behaviorally as a compensatory hyperphagia ${ }^{19}$. A reduction of the expression of central dopamine type 2 receptors (D2 - receptors) would be a possible cause for the deficiency. Genetic studies have shown that obese people have a higher prevalence than lean people of TaqIA1 allele, associated to a lower rate of dopamine D2 receptors in the $\mathrm{CNS}^{20}$. An alternative hypothesis suggests that in obesity there is a dopamine-mediated state of hypersensitivity to environmental cues of high-calorie foods. According to the model of Berridge et al. ${ }^{15}$, when facing multimodal food stimuli, obese individuals would be taken by storm by strong feelings of "wanting". Thus, in obese individuals, the increase in dopamine function caused by food stimuli would result in a compensatory reduction of the expression of central D2 receptors ${ }^{4}$.

Dunn et $a l^{13}$ and Steele et al. ${ }^{8}$ used variations in the expression of D2 receptors in different brain regions as a parameter for the assessment of dopaminergic function. Theories on the causes of variances of the rate of D2 receptors are based on adaptive phenomena inherent to neurotransmitter-receptor interactions well described in the literature, namely, D2-hypersensitisation (or upregulation) and D2-desensitization (or down-regulation) ${ }^{21}$. Hypersensitisation and desensitization occur when there is a need to adjust the input between a neurotransmitter and its receptor ${ }^{21}$ whenever there is fluctuation in the concentration of the neurotransmitter. Thus, a hypersensitisation follows a decrease of the availability of dopamine on the synaptic cleft and a desensitization of such molecular structures follows a local increase of dopamine. In this respect, Dunn et al. ${ }^{13}$ and Steele et al. ${ }^{8}$ showed contradictory results: the former reported decreased postoperative density of D2 receptors in the hypothalamus, amygdala and substantia nigra, and the latter reported an increase of D2 receptors in the ventral striatum, anterior and posterior putamen, and anterior and posterior caudate.

Although initially reasoning that a lack of reward due to the pre surgical decreased expression of D2 receptors and a resulting prejudice to the dopaminergic transmission could stand for possible causes of overeating in obese people, Dunn et al. ${ }^{13}$ documented decrease in the expression of these receptors seven weeks after bariatric surgery in many brain sites. The authors claim that their findings are indirect evidences of the improvement in post surgical dopaminergic transmission, i.e., that the decrease of D2 receptors described by them would be those resulting from receptor desensitization in response to an increase in dopaminergic transmission. Their conclusions seem to be conflicting, since the authors state that a decrease in dopamine results in a primary obstacle to the function of the hedonic pathways in obese people and that the postoperative reduction of D2 receptors reflects an improvement in the dopaminergic transmission. Indeed, the decreased expression of D2 receptors after surgery can be interpreted as resulting from their desensitization in response to an improvement of the dopaminergic transmission following the surgery. However, Dunn et al. ${ }^{13}$ should have documented a presurgical increase (and not a decrease) in the brain expression of D2 receptors in response to a deficiency of the dopaminergic function, in order to give more consistency to their conclusion.

Steele et al. ${ }^{8}$, in turn, described a proportional to weight loss increase in D2 expression 6 weeks after bariatric surgery, in several brain regions related to hedonic feeding. These authors claim that their results can be better explained by the hypothesis that in obese people chronic dopaminergic hyperstimulation induces D2 receptor desensitization, than by theories of constitutional decrease in the expression of these receptors in obesity. For Steele et al. ${ }^{8}$, bariatric surgery would provide a decrease in the anomalous dopaminergic stimulation due to food cues, which, at the molecular level, could have induced hypersensitisation of central D2 receptors. Further, they argue that if abnormal feeding behaviors associated to obesity result from a reduced number of central D2 receptors, bariatric surgery would have produced no effect on their expression.

The discrepancies between the two studies may be explained by some differences between the populations studied. The sample of Dunn et al. ${ }^{13}$ comprises older women with lower scores on a scale for assessing depressive symptoms (Beck Depression Inventory ${ }^{22}$ ) than that of Steele et al. ${ }^{8}$. Dunn et al. ${ }^{13}$ reason that the differences in scores on 
the Beck scale between the two samples could explain the opposite results, since the population of Steele et al. ${ }^{8}$ seemed "more depressed" than theirs. Dunn et al.13 argue that, as depressive states may be secondary to hypodopaminergic states, the differences between the two populations regarding depressive symptoms could be a confounding factor in interpreting the results. We do not believe this to be the case because: 1. Depressive symptoms are not exclusively secondary to hypodopaminergic states and can also occur in hyposerotoninergic and hyponoradrenergic states; 2. Scores on instruments such as the BDI do not reflect, necessarily, changes of central neurotransmitters. As the authors state ${ }^{13}$, age differences of the two samples may also explain the divergent results between their and Steele et al.'s study. Likewise, many studies have shown age variation in the expression of D2 receptors in striatal ${ }^{23}$ and extrastriatal regions ${ }^{24}$. However, it is important to highlight that concepts such as up and downregulation of receptors, while important in understanding mood disorders and disorders of hedonic insufficiency, such as substance use disorders and obesity, should not be considered sufficient for their comprehension. Certainly, central mechanisms regarding incentive salience in obesity must not be understood as consequences of mere changes in synaptic dopaminergic signaling.

Hunt et al. ${ }^{11}$ studied differences in patterns of activation and deactivation of brain areas before and after feeding in operated obese (RYGBP), non-operated obese and lean subjects, before and after eating, showing significant differences between groups. After bariatric surgery, obese subjects started to show a pattern of brain activation similar to that of lean individuals, which would reflect a change in the communication between the brain and the digestive system caused by bariatric surgery and seems to be associated with anecdotal reports of increased sensation of satiety after surgery. Unlike what happened with the non-operated obese, operated ones showed decreased radioligant uptake after feeding in the orbitofrontal cortex (OFC), DLPFC, precuneus and thalamus, indicating decreased activity of these regions after surgery.

OFC comprises MCPF regions, hypothalamus, amygdala, insula, operculum, ventral and dorsal striatum and dopaminergic midbrain ${ }^{25}$. Its functions range from sensory integration and modulation of autonomic reactions to learning, prediction, decision making and goal-directed behavior, and its orbital portion is important for the regulation of food intake ${ }^{25}$. Damage to the OFC decreases cognitive control and induces perseverative behaviors ${ }^{25}$. Post-surgical decrease in the activity of this region and DLPFC after feeding arises from the normalizing of the function of subcortical structures that process homeostatic, emotional and hedonic value of the food, thus reducing top-down inhibitory inputs to them.
Ochner et al. ${ }^{9}$ found significant differences in the activation patterns of key regions concerning central processing of incentive salience after visual and auditory cues of foods containing different levels of calories, before and after RYGBP. These regions included the mesolimbic reward circuitry, such as TVA, ventral striatum and putamen. The authors reported decreased activation of these regions after surgery, changes that were even more pronounced following cues of high-calorie foods. Their findings suggest that in obese people some brain areas become more active after exposition to cues of caloric foods. This can be interpreted, from a behavioral standpoint, that obese subjects might sense an increased craving (or increased "wanting") for high-calorie foods, a condition likely to be regulated by bariatric surgery. Furthermore, bariatric surgery would promote advantageous and selective changes in food preferences, at least acutely. The authors also reported decreased postoperative brain activation in other regions, such as the middle temporal gyrus, the inferior parietal lobule and precuneus. Even without a clearly defined function, it is believed that the middle temporal gyrus is related to distances evaluation, recognition of familiar faces and meaning of read words ${ }^{26}$. Although its activation may not have been stimulus specific, but merely associated with the design of the experiment, which included visual and auditory stimuli on food, decreased postoperative of middle temporal gyrus activity can be linked to the reduction of the salience to food cues. This could also account to the postsurgical activation of the inferior parietal lobule, whose functions include, among others, the interpretation of sensory information. In other words, the mere presentation of sensory cues and not their contents themselves could have recruited this region.

Bruce et al. ${ }^{12}$ used FMRI to evaluate patients before and 12 weeks after AGB. During the scans, photographs with and without food context were presented to the experimental subjects. Similarly to the study of Ochner et al. ${ }^{9}$ they found decreased activation of areas related to motivation and reward, such as MPFC, parahippocampal region, insula and inferior frontal gyrus after exposure to images of food, after AGB.

MPFC is associated with fear reactions, risk evaluation and decision making ${ }^{17}$ and seems to have some hedonic activity that would be mediated through its connectivity with the $M F B$, given that the stimulation of the MPFC activates the mesencephalic dopaminergic system ${ }^{17}$. Such connections are, however, still obscure. Although stimulation of MCPF regions innervated by dopamine is rewarding, the extent of this response is weaker than the direct stimulation of the MFB, which additionally has shorter refractory periods ${ }^{17}$. Therefore, the post-BGA decrease in MPFC activity may be related to declining feelings of 'wanting' and normalization of disrupting food seeking behaviors. 
Bruce et al. ${ }^{12}$ also documented increased activation of the anterior prefrontal cortex (APFC), an area associated to behavioral inhibition. In fact, while some authors describe increased activity in inhibitory areas ${ }^{11}$ after bariatric surgery, others show decreased activity ${ }^{14}$. These contradictions could be explained considering that, typically, the DLPFC participates in processing attempts to inhibit the consumption of high-calorie foods and, therefore, would be reciprocally activated with regions related to the processing of pleasure and reward associated to cues of such foods. After bariatric surgery obese people would perceive highly caloric foods as less rewarding, hence requiring less inhibitory effort and consequently, lesser engagement of DLPFC. Despite the inconsistencies on which inhibitory areas have their actions altered in obesity, there is some evidence indicating that in obese people food cues promote greater DLPFC activation and feeding promotes reduction of the activation of this $a^{2} a^{16}$. Therefore, lean subjects regulate properly their hedonic feeding for the reason that the expectation of feeding recruits not only the mesolimbic reward circuits but also its inhibitory counterpart, as well as the act of feeding itself enhances the power of the inhibitory activity, processes that are disrupted in obese individuals, mainly at the expense of a reduction of the inhibitory activity that must follow a meal. A recent study ${ }^{27}$ compared the activation patterns of reward and inhibitory circuits in individuals suffering from simple obesity and Prader-Willi syndrome (PWS) shed some light on this issue. PWS is a genetic condition characterized by morbid obesity due to hyperphagia and extreme hypergrelinemy. In PWS central mechanisms of regulation of feeding behavior are much more extensively damaged than in simple obesity ${ }^{27}$. In this study, patients with PWS showed significantly greater activation of subcortical reward circuitry and impoverished activity of inhibitory circuits (mainly DLPFC and OFC) than individuals with simple obesity. These results suggest that subtypes of obesity with lower genetic diathesis than PWS would display distinct patterns of frontocortical inhibitory response.

Ochner et al. ${ }^{10}$ suggest that decreased mesolimbic responsiveness to food cues in patients undergoing RYGBP may be related to alterations of intestinal peptides observed after surgery (most of these alterations include increases in peptide YY and GLP-1, although slight increases of ghrelin have also been documented). Postoperative increases of these peptides would occur as a result of the increased rate of passage of nutrients through the digestive tract and its faster filling. Surprisingly, the main finding of this study was that, after RYGBP, experimental subjects showed decreased activation of areas such as the gustative cortex and mesencephalic pathways following food cues only in fasting states, contradicting the initial hypothesis that the post-surgical change on the dynamics of gastric filling and its effect on the release of gut peptides have some influence on the regulation of hedonic feeding behavior by means of reducing the activity of reward pathways. It is well known that substances produced in the periphery exert actions in the CNS, even though the mechanisms by which these actions take place are not fully understood, e.g., the presence of leptin receptors in the VTA dopamine neurons indicates that this substance modulates mesencephalic circuits'. Likewise, ghrelin exerts its orexigenic effects by increasing hedonic responses to food, and peptide YY promotes its anorectic effects through direct actions on arcuate nucleus of hypothalamus ${ }^{28}$.

More recently, Ochner et al. ${ }^{14}$ reported a significant reduction in the responsiveness of mesolimbic circuits and of the desire to eat ("wanting") after food cues, but not of the pleasure to eat ("liking") in operated obese people, 30 days after RYGBP, in comparison with the preoperative status. In agreement with other studies, these authors also documented decreased postoperative activation of mesencephalic structures, improving disrupted behaviors associated with incentive salience, and of structures such as the precuneus and inhibitory regions such as DLPFC.

Some brain areas are noteworthy for having changes in their patterns of activation after bariatric surgery documented in more than one of the studies included.

The precuneus, located in the posteromedial parietal cortex and rarely injured in accidents or strokes, is still an area to be functionally mapped ${ }^{29}$. Its functions range from the processing of egocentric and allocentric spatial relationships, aspects of consciousness, self-monitoring and memory ${ }^{29}$. Regarding mnemonic processes, it is suggested that the precuneus participates in the processing of episodic memory, which is used for storage and recall of events previously lived ${ }^{29}$, and the elaboration of mental images. The precuneus is very active in neuroimaging studies that use tasks in which words "highly imaginable" are presented to experimental subjects and some authors have speculated that this region would be the "mind's eye"29. Accordingly, experimental studies whose design involves the presentation of auditory cues, such as Ochner et al.'s9, must recruit the precuneus in developing mental images. Nevertheless, the decrease in precuneus activity documented in this and other manuscripts ${ }^{10,11}$ could be explained as due to the reduction of postoperative magnitude of hedonic and emotional inputs from regions such as TVA, ventral striatum, putamen and amygdale to precuneus, giving rise to mental images less emotionally loaded.

The insula also takes part in the management of mental images, and the decrease in its activity after $A G B^{12}$ is associated to the contribution of this brain structure in the regulation of homeostatic and hedonic feeding. Insula lies deeply in the lateral sulcus and is activated in cravings for 
foods and psychoactive substances ${ }^{30}$. Insula's front portion is involved in processing of taste and smell, as well as the feeling of disgust, and the posterior portion deals with the production of maps and images of the body in close relation with somatosensory cortex, by means of information emerging from the nucleus of the solitary tract and the parabrachial nucleus, which carry information about the body $\operatorname{states}^{30}$. The post-BGA decrease in insula activity may also explain the reduction in motivation for food after the procedure reported in the study by Bruce et $\mathrm{al}^{12}$.

\section{CONCLUSIONS}

The neuroimaging studies reviewed here suggest that bariatric surgery, particularly RYGBP, can promote changes in responsivity patterns of brain structures related to the processing of reward and cognitive control. These findings demonstrate that, after bariatric surgery, obese people can benefit from a functional reorganization of neural systems regarding the ways they seek caloric foods, get pleasure from them, as well as control their intake. The results here discussed also support a new and favorable expectation on the part of bariatric patients, who may believe that their weight loss also has its origin in a change in attitude toward food. These results, however, must be considered preliminary, since the manuscripts selected have methodological limitations, such as small sample sizes, predominantly female populations and lack of adequate control of other conditions that might affect brain activation, as comorbidities of obesity with psychiatric disorders, such as depression and substance use disorders. Nevertheless, the results seem to support the accounts given by many patients after surgery, not only about changes in food preferences (Berridge's "wanting" dimension), but also in the palatability of particular foods (Berridge's "liking" dimension), as well as the increase of self-control over food intake. This reinforces the idea that bariatric surgery is not a purely restrictive alternative for the treatment of obesity, but may exert its effects through actions on the CNS. More studies are needed to clarify which mechanisms underlie these actions, as well as if they are lasting.

Limitations of our review include the small number of included manuscripts. We believe this is due the fact that the study of changes in central regulation of feeding behavior after bariatric surgery is a scientific issue that is only beginning to arouse the interest of bariatric surgeons and their staffs.

\section{INDIVIDUAL CONTRIBUTIONS}

Hélio Tonelli - Principal investigator. Contributed to conception, design analysis and interpretation of the data.
Also contributed to drafting the article, revising it critically and approval of the final version to be published.

Fernanda Mathias Sartori - Search, data collection, analysis, revision, bibliography and copy-editing the article.

João Caetano Dallegrave Marchesini - Search, data collection, analysis, revision, bibliography and copy-editing the article.

João Batista Marchesini - Search, data collection, analysis, revision, bibliography and copy-editing the article.

Denise Gianoti Tonelli - Search, data collection, analysis, revision, bibliography and copy-editing the article.

\section{DISCLOSURES}

The authors report no proprietary or commercial interest in any product mentioned or concept discussed in this article.

\section{REFERENCES}

1. Pandit R, de Jong JW, Vanderschuren LJMJ, Adan RAH. Neurobiology of overeating and obesity: the role of melanocortins and beyond. Eur J Pharmacol. 2011;660:28-42.

2. Johnson AW. Eating beyond metabolic need: how environmental cues influence feeding behavior. Trends Neurosci. 2013;36(2):101-9.

3. Carnell S, Gibson C, Benson L, Ochner CN, Geliebter A. Neuroimaging and obesity: current knowledge and future directions. Obes Ver. 2012;13(1):43-56.

4. Gao Q, Horvath TL. Neurobiology of feeding and energy expenditure. Annu Ver Neurosci. 2007;30:367-98

5. Claes L, Vandereycken W, Vandeputte A, Braet C. Personality subtypes in female pre-bariatric obese patients: do they differ in eating disorder symptoms, psychological complaints and coping behavior? Eur Eat Disorders Rev. 2013;21:72-7.

6. Rao R. Bariatric surgery and the central nervous system. Obes Surg. 2012;22(6):967-78.

7. Miller EK. The prefrontal cortex and cognitive control. Nat Rev Neurosci. 2000;1:59-65.

8. Steele KE, Prokopowicz GP, Schweitzer MA, Magunsuon TH, Lidor AO, Kuwabawa H, et al. Alterations of central dopamine receptors before and after gastric bypass surgery. Obes Surg. 2010;20:369-74.

9. Ochner CN, Kwok Y, Conceição E, Pantazatos SP, Puma LM, Carnell S, et al. Selective reduction in neural responses to high calorie foods following gastric bypass surgery. Ann Surg. 2011;253(3):502-7.

10. Ochner $C N$, Laferrère $B$, Afifi L, Atalayer $D$, Geliebter $A$, Teixeira J. Neural responsivity to food cues in fasted and fed states pre and post gastric bypass surgery. Neurosci Res. 2012;74(2):138-43.

11. Hunt KF, Dunn JT, Pernet AM, Marsden PK, Amiel SA. The brain's response to food ingestion after Roux-en-Y gastric bypass: a [18F]-fluorodeoxyglucose positron emission tomography (FDG-PET) study. Diabetologia. 2011;54(1):S63.

12. Bruce JM, Hancock L, Bruce A, Lepping RJ, Martin L, Lundgreen JD, et al. Changes in brain activation to food pictures after adjustable gastric banding. Surg Obes Relat Dis. 2012;8:602-8.

13. Dunn JP, Cowan RL, Volkow, ND, Feurer ID, Li R, Williams DB, et al. Decreased dopamine type 2 receptor availability after bariatric surgery: preliminary findings. Brain Res. 2010;1350:123-30.

14. Ochner CN, Stice E, Hutchins E, Affif L, Geliebter A, Hirsch J, et al. Relation between changes in neural responsivity and reductions in desire to eat high-calorie foods following gastric bypass surgery. Neuroscience. 2012;209(3):128-35. 
15. Berridge KC, Robinson TE, Aldridge JW. Dissecting components of reward: 'Iiking', 'wanting', and learning. Curr Opin Pharmacol. 2009;9(1):65-73.

16. Ho A, Kennedy J, Dimitropoulos A. Neural correlates to food-related behavior in normalweight and overweight/obese participants. PLoS 0NE. 2012;7(9)e45403:1-9.

17. Wise RA. Forebrain substrates of reward and motivation. J Comp Neurol. 2005;493(1):11521.

18. Laruelle M, Kegeles LS, Abi-Dargham A. Glutamate, dopamine, and schizophrenia: from pathophysiology to treatment. Ann N Y Acad Sci. 2003;1003:138-58.

19. Comings DE, Blum K. Reward deficiency syndrome: genetic aspects of behavioral disorders. Prog Brain Res. 2000;126:325-41.

20. Wang GJ, Volkow ND, Logan J, Pappas NR, Wong CT, Zhu W, et al. Brain dopamine and obesity. Lancet. 2001;3:354-7.

21. Kostrzewa RM, Kostrzewa JP, Brown RW, Nowak P, Brus R. Dopamine receptor supersensitivity: development, mechanisms, presentation, and clinical applicability. Neurotox Res. 2008;14(2-3):121-8.

22. Beck AT, Steer RA, Ball R, Ranieri W. Comparison of Beck Depression Inventories -IA and -II in psychiatric outpatients. J Pers Assess. 1996;67:588-97.
23. Volkow ND, Logan J, Fowler JS, Wang GJ, Gur RC, Wong C, et al. Association between age-related decline in brain dopamine activity and impairment in frontal and cingulate metabolism. Am J Psychiatry. 2000;157(1):75-80.

24. Kaasinen V, Kemppainen N, Någren K, Helenius H, Kurki T, Rinne J0. Age-related loss of extrastriatal dopamine D(2) -like receptors in women. J Neurochem. 2002;81(5):1005-10.

25. Kringelbach ML. The human orbitofrontal cortex: linking reward to hedonic experience. Nat Rev Neurosci. 2005;(6):691-702.

26. Corkin S, Amaral DG, González G, Johson KA, Hyman BT. H. M.'s medial temporal lobe lesion: findings from magnetic resonance imaging. J Neurosci. 1997;17(10):3964-79.

27. Holsen LM, Savage CR, Martin LE, Bruce AS, Lepping RJ, Ko E, et al. Importance of reward and prefrontal circuitry in hunger and satiety: Prader-Willi syndrome vs. simple obesity. Int J Obes (Lond). 2012;36(5):638-47.

28. Suzuki K, Jayasena CN, Bloom SR. Obesity and appetite control. Exp Diabetes Res. 2012;2012:824305

29. Cavanna AE, Trimble MR. The precuneus: a review of its functional anatomy and behavioural correlates. Brain. 2006:129:564-83.

30. Damasio A. Self comes to mind. New York, NY: Pantheon Books. Random House; 2010. 